\title{
Exploración sobre la revalorización rural y la calidad de vida en el partido de General Pueyrredón (Sudeste de la provincia de Buenos Aires, Argentina). El caso de las estancias turísticas La Reserva y La Trinidad
}

Matías Adrián Gordziejczuk ${ }^{1}$

Universidad Nacional de Mar del Plata

Tipo de trabajo: Artículo

Material original autorizado para su primera publicación en el Journal de Ciencias Sociales, Revista Académica de la Facultad de Ciencias Sociales de la Universidad de Palermo.

Recibido: 26-10-2014

Aceptado: 10-12-2014

\section{Resumen}

El propósito de este artículo es explorar el proceso contemporáneo de revalorización del espacio rural a partir de un análisis centrando en su capacidad creciente de absorber flujos de población impulsados por la necesidad de ocio y turismo. El estudio sobre la turistificación del espacio rural trata de combinarse con aportes centrados en la calidad de vida porque se considera que la dinámica ocio y turismo rural/ calidad de vida poco ha sido abordada hasta el momento. Se tiene en cuenta que la relación entre estos conceptos incluye tanto a quienes demandan la actividad de ocio y turismo rural (turistas y visitantes urbanos) como a quienes la ofrecen (productores, responsables de establecimientos rurales, pobladores de pequeñas localidades).

El abordaje teórico es acompañado de una aplicación de naturaleza cualitativa sobre el caso del turismo de estancia en el partido de General Pueyrredón (Sudeste de la provincia de Buenos Aires, Argentina). La estancia constituye una unidad de observación relevante por ser una de las formas tradicionales de organización espacial de las unidades de producción de la región pampeana; en ellas se realizaron entrevistas informales a quienes despliegan la actividad. En esta oportunidad se plantea que, en las estancias testigo, la actividad complementaria del ocio y turismo rural resultaría ser una estrategia propulsora de una mejor calidad de vida por la satisfacción de necesidades de

\footnotetext{
${ }^{1}$ Profesor en Geografía, Becario de la Universidad Nacional de Mar del Plata e Integrante del Grupo de Estudios Sobre Población y Territorio. E-mail: ma_gordziejczuk@hotmail.com
} 
tipo materiales y no materiales.

La información empírica obtenida se vincula con los preceptos sobre la revalorización del espacio rural y la calidad de vida. Concretamente, se trata de conocer cómo se califica al espacio rural y urbano, qué factores intervinieron en las estancias para poner en marcha la actividad y cómo el ocio y turismo rural aportan una mejor calidad de vida a quienes lo demandan y lo ofrecen.

Palabras clave: revalorización rural- ocio y turismo- calidad de vida- turismo de estancia

\section{Abstract}

The purpose of this article is to explore the contemporary process of revaluation of rural areas from a focus on its growing ability to absorb population flows driven by the need for leisure and tourism analysis. The study of the touristification of rural areas is combined with contributions focused on quality of life because it is considered that the dynamic rural leisure and tourism/ quality of life little has been addressed so far. It takes into account the relationship between these concepts includes both those demanding leisure activities and rural tourism (tourists and city visitors) as to the offer (producers, responsible for rural facilities, residents of small towns).

The theoretical approach is accompanied by a qualitative application on the case of farm residency tourism in the General Pueyrredón district (Southeast of the province of Buenos Aires, Argentina). The farm residency is a relevant unit of observation as one of the traditional forms of spatial organization of the production units of the Pampas area; those to deploy semi-structured interviews were conducted activity. This time it is argued that, in the farm residency observed, additional leisure activities and rural tourism strategy would be driving a better quality of life for the satisfaction of material and nonmaterial needs.

The empirical information obtained is related to the provisions on the revaluation of the rural areas and the quality of life. It is about knowing how rural and urban space qualifies, what factors contributed to the farm residency to start the activity and how rural leisure and tourism provide a better quality of life to those who need it and offer it.

Keywords: rural revaluation- leisure and tourism- quality of life- farm residency tourism 


\section{Introducción}

El propósito de este artículo es explorar el proceso contemporáneo de revalorización del espacio rural. La sociedad occidental exhibe en las últimas décadas un cambio de actitud frente al espacio rural producto de la apreciación de cualidades ignoradas anteriormente. Desde el momento en que la ciudad y el modo de vida urbana revelaron externalidades negativas, como la excesiva artificialización del medio construido, la contaminación ambiental, sonora y visual, la violencia y la congestión vehicular, el espacio rural empezó a ser percibido como un marco de vida comparativamente más ameno. Debido a esto, el campo aumentó su atractivo y empezó a recibir habitantes procedentes de ciudades impulsados por motivos como cambio de residencia, relocalización del lugar de trabajo y necesidad de ocio y esparcimiento.

Actualmente, hablar del espacio rural como un todo homogéneo resulta inapropiado, el campo se ha complejizado y ha adquirido múltiples funciones y significados, ya que no sólo remite a las actividades primarias y a la población ocupada en labores agropecuarias (Nates Cruz y Raymond, 2007). Por detrás de este proceso social y cultural, la calidad de vida se vuelve una categoría de análisis crucial, porque la revalorización de lo rural significa ver lo rural como una alternativa de vida más tranquila, natural y amena (Pérez, 2001).

El trabajo que aquí se presenta aborda la revalorización del espacio rural desde el caso particular de su creciente capacidad de absorber flujos de población impulsados por la necesidad de ocio y turismo, actividades pertenecientes al sector de servicios comúnmente asociadas con el espacio urbano. El análisis se mantiene al margen de las amplias discusiones sobre qué es realmente el ocio y el turismo rural, ya que se trata de conceptos polisémicos donde, por ejemplo, no hay acuerdo acerca de las actividades y modalidades que debe y no debe incluir. Además, a la complejidad de los términos ocio y turismo se le debe sumar las discusiones propias del concepto rural.

Podría avecinarse que tanto para quienes demandan la actividad, básicamente habitantes urbanos, como para quienes la ofrecen, el ocio y turismo rural se presentan como una combinación de fuerzas para el logro de una mejor calidad de vida, o por la satisfacción de necesidades no sólo materiales, sino también intangibles, es decir, relacionadas con la identidad, la autoestima, el enriquecimiento personal y la ocupación del tiempo libre. Como producto de esta combinación, ciertos recortes del espacio rural se ven implicados en un proceso de turistificación del territorio. 
A continuación de la perspectiva teórica y metodológica, se presenta una aplicación de naturaleza cualitativa sobre el caso del turismo de estancia en el partido de General Pueyrredón (sudeste de la provincia de Buenos Aires, Argentina). La estancia constituye una unidad de observación relevante por ser una de las formas tradicionales de organización espacial de las unidades de producción de la región pampeana, área donde se localiza el distrito en cuestión. Durante los últimos años, muchas estancias han aprovechado su infraestructura ociosa, capital cultural y paisaje enverdecido para desarrollar el ocio y turismo rural, y a su vez complementar los ingresos provenientes de la ganadería y agricultura. Al mismo tiempo, la idiosincrasia y el valor histórico y cultural que conservan generan atracción y curiosidad en un limitado segmento de la población local y de turistas internacionales, favoreciéndose así el crecimiento de la actividad.

El estudio es de carácter exploratorio, ya que se trabaja a partir de las primeras observaciones e ingresos al campo. Se intenta vislumbrar potenciales interrogantes que ameriten futuras investigaciones sobre la temática y el territorio seleccionado. El proceso de investigación se basó en la realización de entrevistas informales a desarrolladores de turismo de estancia en el partido de General Pueyrredón. La información empírica obtenida se vincula con los preceptos sobre la revalorización del espacio rural y la calidad de vida. Concretamente, se trata de conocer cómo se califica al espacio rural y urbano, qué factores intervinieron en las estancias para poner en marcha la actividad y cómo el ocio y turismo rural aportan una mejor calidad de vida a quienes lo demandan y lo ofrecen.

\section{Perspectiva teórica}

Podría decirse que uno de los procesos contemporáneos que más ha repercutido sobre el territorio de las sociedades occidentales ha sido la revalorización del espacio rural. Durante las últimas décadas, y después de años de olvido, el campo se ha complejizado y ha adquirido nuevos significados producto de una heterogeneidad motorizada por las diferencias de localización, de composición socio-económica, de políticas locales y de actitudes individuales (Nates Cruz y Raymond, 2007). Como consecuencia, se observan en el espacio rural actividades, funciones, formas de vida y de territorios, diferentes de las tradicionales.

Como bien señala Hiernaux (2000), la revalorización del espacio rural se encuadra en un proceso de inversión de las ideas asociadas a lo urbano y lo rural: 
Mientras que lo urbano adquiere características de unicidad en la sucesión de imágenes repetidas a través del mundo (...), sólo el mundo rural admite la continuidad y la permanencia de imágenes que provienen de la historia más remota de los pueblos. Por ello, la valoración de lugares campiranos es más fuerte que nunca. (Hiernaux, 2000, p. 34)

De manera progresiva, el campo va siendo adjetivado positivamente, en contraposición a etapas anteriores cuando se calificaba como espacio atrasado y poco sofisticado. Se ha vuelto común para los que residimos en las ciudades oír características atractivas del campo, entre las que sobresalen su capacidad para acercarnos a la naturaleza, recordarnos las tradiciones y despertarnos el interés por experimentar el alejamiento y la tranquilidad.

La multifuncionalidad actual del espacio rural y su revalorización provienen del fortalecimiento de características antes poco visibles, que son producto de una adaptación del campo y la ciudad al nuevo momento coyuntural y estructural (Mikkelsen, 2008). Se trata de un proceso complejo, cuyo abordaje científico suele realizarse a partir del estudio de temáticas más concretas. Dentro de la Geografía, la relocalización de industrias, la neo-ruralidad y, como se presenta en este caso, la turistificación del espacio rural, han sido las áreas más analizadas.

La turistificación del campo implica la transición del espacio rural hacia una nueva funcionalidad (CruzCoria y otros, 2012), refiere a la ampliación del ocio y turismo sobre el espacio rural, o su capacidad creciente de absorber flujos de población impulsados por la necesidad de ocio y esparcimiento.

Se considera que una perspectiva geográfica centrada en la turistificación del campo comprende, por un lado, el conocimiento sobre la (re)producción del espacio geográfico rural y las dinámicas socio-espaciales generadas por la relación ciudad-campo. A la vez, la oferta de actividades de ocio y turismo derivadas de la revalorización del espacio rural "cambia las estructuras, las esencias, los movimientos y los significados de los objetos y acciones" (de Souza, 2012, p. 5). Por otro lado, explorar el proceso de construcción de atractividad turística a partir de la promoción pública y privada (Troncoso, 2007), así como también el discurso referido al territorio se vuelve útil para reconocer la oferta de atractivos, es decir, la base sobre la que se asienta la turístificación del espacio rural en un determinado territorio.

El fenómeno de la turistificación del espacio rural tiene su origen en la conjunción de la demanda y de las necesidades de habitantes urbanos y la implementación de estrategias territoriales endógenas, es decir, propias de los pobladores rurales. Estos aspectos han sido ampliamente abordados desde las 
Ciencias Sociales, junto a otros como el origen del ocio y turismo rural o las externalidades positivas y negativas que ocasiona. Sin embargo, poco se ha analizado a la luz del concepto de calidad de vida, siendo que la turistificación del espacio rural sería una expresión territorial de la búsqueda de una mejor vida por parte de los sujetos involucrados en la actividad del ocio y turismo rural: turistas/ visitantes urbanos y anfitriones turísticos, es decir, productores/ responsables de establecimientos rurales/ pobladores de pequeñas localidades.

La calidad de vida es un concepto dinámico que se encuentra relacionado con los valores predominantes en un contexto espacial, temporal y social determinado. Al margen de los conceptos de bienestar y condiciones de vida, que se hallan condicionados por el nivel de ingreso, la posibilidad de consumo y la satisfacción de necesidades básicas o materiales, la calidad de vida incluye principios que se definen considerando el contexto que se va a analizar. En este caso se establece que entrar en contacto con el espacio rural para satisfacer la necesidad de ocio y turismo sería un principio de calidad de vida, afirmación que se realiza a partir de tener como referencia al urbanita occidental contemporáneo.

Dicho de otra forma, la calidad de vida es un concepto independiente del nivel socio-económico de los sujetos. Implica traer a consideración la base territorial sobre la cual se desarrolla la vida y las necesidades, en términos amplios, que surgen sobre ese territorio en un momento específico. Se puede decir que "la calidad de vida comprende la satisfacción de necesidades materiales y no materiales y los deseos y aspiraciones de las personas (...) El concepto de calidad de vida es una noción propia de cada cultura y tiene un cierto contenido de opcionalidad" (López, 2007, p. 3).

Se trata de un concepto de carácter evaluativo (Lucero y otros, 2008, p. 79), abordado tradicionalmente a partir de indicadores estadísticos y metodologías cuantitativas, "no siendo usual la utilización de indicadores cualitativos que permitan conocer las percepciones y opiniones de los ciudadanos" (Tonon y Castro Solano, 2012, p. 157). No obstante, y al igual que las estadísticas generales, el enfoque micro de la calidad de vida basado en opiniones personales cobra cada vez mayor fuerza, producto de su posibilidad de ser vinculado con procesos mayores como el devenir social y económico de un país.

En esta oportunidad, se plantea que tanto los urbanitas que demandan ocio y turismo rural, como el conjunto de actores que desarrollan la actividad, actuarían merced a una mejoría en su calidad de vida. Para los primeros, el espacio rural constituye un objeto de consumo construido desde la ciudad (Posada, 1999) donde, siguiendo a Muñoz Escalona (2013), lo que se busca es un medio con 
aspecto campirano en el cual se pueda desarrollar un modo de vida citadino:

Se ha puesto de moda pasar los fines de semana y las vacaciones en el campo (...) Pero, cuando buscamos lo rural, sólo encontramos un sucedáneo de lo rural, un remedo torpe de lo que fue antaño lo rural. Aunque lo cierto es que lo queremos así. Queremos el medio rural, pero sin perder las comodidades urbanas (Muñoz Escalona, 2013, p. 1).

Con una demanda de este tipo avanza la urbanización del campo, que promueve la conversión de la esencia del espacio rural sin extinguir parte de sus singularidades o atractivos. Paralelamente, se configura una nueva arquitectura rural cercana a los modelos urbanos para recibir y alojar personas (de Souza, 2012).

Para los que ofrecen la actividad, la infraestructura ociosa de valor histórico presente en muchos establecimientos, el paisaje agropecuario e inhóspito de la llanura pampeana, la gastronomía y la cultura gaucha, han sido los principales recursos sobre los que se basa la oferta de ocio y turismo rural. Sobre la base de estas características, el Estado provincial ha contribuido a promocionar los atractivos del campo pampeano, permitiendo así la revalorización del espacio rural. A modo de ejemplo, la folletería de la Secretaría de Turismo de la provincia de Buenos Aires, si bien destaca la gran diversidad de su territorio, expresa: Las pampas de Buenos Aires tienen sus símbolos en las estancias y el gaucho. Esta figura legendaria, diestra en las faenas de campo, permite vivir una tradición rural centenaria y peculiar en pleno siglo XXI.

Más allá del horizonte, la Provincia invita a disfrutar de sus vastas llanuras y verdes pastizales, a recorrer estancias, granjas, chacras, casas de campo, ranchos y molinos; haciendas, cultivos y caminos arbolados; a escuchar historias de gauchos contadas en viejos almacenes, postas y pulperías.

Conocer el medio rural en contacto con la fauna y la flora de las pampas supone no sólo hacerlo como simple espectador, sino como protagonista de las faenas, ordeñando una vaca, amasando pan casero, alimentando animales de granja o fabricando quesos; experimentando las emociones y sensaciones que el campo puede brindar. 
en el ámbito de lo privado, los ingresos generados no escapan de la unidad de producción. Al mismo tiempo, el trato familiar que se brinda transforma esta modalidad en muy demandada por quienes exigen que se les cuente la historia (Craviotti, 2002). Según Espil (2005), las estancias turísticas son verdaderos escenarios de actuación:

Se produce una puesta en escena para el turista, junto a una actuación por parte de todo el equipo de trabajo. Al turista se lo incorpora a un entorno preparado de antemano, y presentado de una manera que remita a experiencias auténticas a ser vividas por el visitante. (Espil, 2005, p. 11)

La experiencia de ocio y turismo rural se presenta como una actuación necesaria para cumplir con las expectativas de turistas y visitantes urbanos, quienes perciben al espacio rural como un entorno ameno desde el punto de vista natural y cultural. Por detrás de esta difícil labor de los anfitriones turísticos, que además debe resultar extraña para quienes comúnmente han desarrollado tareas agropecuarias, se encuentra la necesidad de ampliar los ingresos procedentes de las actividades primarias, debido a las recurrentes crisis en las que se ve envuelto el sector. Se trata de una estrategia adoptada por numerosas familias rurales que posibilita la diversificación de ingresos y el sostenimiento del empleo.

Comúnmente, las labores de servicio en sí y el mantenimiento del entorno tienen como protagonista a la mujer. Así como el ocio y turismo facilitan la incorporación de la mujer en la economía rural, también son un instrumento para transformar su vida cotidiana. García y otros (2001) llegan a la conclusión de que el desarrollo de las tareas de servicio produce satisfacción en muchas mujeres que viven en áreas rurales, ya que las conecta con otros ámbitos como el de tomar decisiones, elevando su autoestima y favoreciendo su calidad de vida. Además, contribuye a la formación de una identidad y reconocimiento por fuera del ámbito familiar. "Estas mujeres ganaron un espacio propio a partir de la crisis, pero probablemente no lo abandonarán si la situación mejora" (García y otros, 2001, p. 8).

Para finalizar este apartado, se retoma que la revalorización contemporánea del espacio rural repercute sobre un entramado social heterogéneo y comprende toda una serie de fenómenos cuya explicación implica considerar la relación campo-ciudad. Uno de los fenómenos que se destaca es el ocio y turismo rural, actividad que, por un lado, atrae flujos de población urbana por el consumo y contemplación de algunos atractivos del campo (infraestructura, cultura, paisaje), y por otro, incita la participación de la mujer en la economía del espacio rural. 
Paralelamente, la actividad se relacionaría con la búsqueda de mejor calidad de vida, no sólo por su contribución a la generación de ingresos, sino también por brindar la posibilidad de esparcimiento, diversión y ocupación del tiempo libre, enriquecimiento personal y ampliación de conocimientos sobre la ruralidad, y de manera potencial, elevación de autoestima, reconocimiento social y formación de una identidad.

\section{Perspectiva metodológica}

La metodología implementada es de naturaleza cualitativa, sin embargo, la sistematización de datos e información procedentes de fuentes estadísticas del INDEC² (Censos Nacionales de Población, Hogares y Viviendas y Censo Nacional Agropecuario) acompañan el desarrollo de la investigación, y respaldan el proceso de interpretación de las entrevistas informales realizadas a responsables de estancias que ofrecen ocio y turismo rural en el partido de General Pueyrredón.

Dos fueron las estancias testigo, y en ambas la persona entrevistada, en ambos casos mujeres, fue la propietaria del establecimiento. La entrevista estuvo basada en tres apartados: identificación de la estancia y actividades desarrolladas, motivaciones para impulsar el ocio y turismo, y adaptaciones para su incorporación y, finalmente, características y opiniones de los turistas y visitantes. El guión de entrevista se adaptó de forma tal que los entrevistados pudieran brindar respuestas de carácter cerrado y también testimonios amplios, que rescatasen apreciaciones del espacio rural y urbano e incluyeran insinuaciones sobre la calidad de vida de ellos y de los turistas y visitantes. La respuesta fue combinándose con la conversación informal, la repregunta y la visita guiada por cada establecimiento.

La folletería y publicidad emitida desde el Ente Municipal de Turismo (EMTur) fue utilizada como base de datos para la búsqueda de unidades de observación. Por medio de correos electrónicos y llamados telefónicos se logró concretar un encuentro en cada establecimiento. Vale aclarar que, como ambos casos tienen orígenes y propuestas diferentes, lo que se plantea no es una aplicación de carácter comparativo y sí exploratorio, dado que se trabaja a partir de los primeros datos e ingresos al campo.

${ }^{2}$ Instituto Nacional de Estadísticas y Censos 
Turismo de estancia en el partido de General Pueyrredón: el caso de La Reserva y La Trinidad

El partido de General Pueyrredón (mapa 1) forma parte de la región pampeana, área argentina que sobresale por su perfil agroproductivo, pero también por la cantidad de establecimientos rurales abiertos al ocio y turismo. Asimismo, es el territorio donde las explotaciones agropecuarias con recreación y turismo cultural y el número de plazas, o la capacidad de hospedaje, duplican cómodamente al resto de las regiones del país (ver tabla 1).

Nogar y Capristo (2010) destacan que un fuerte perfil agroexportador, como el de la región pampeana, dificulta percibir procesos vinculados a otras actividades y funciones asignadas al espacio rural. Sin embargo, la turístificación del espacio rural pampeano es un proceso creciente y que se afianza día a día. Por más que esté destinado a un limitado segmento de la población local y de turistas internacionales, el análisis de este fenómeno adquiere relevancia si se piensa en los efectos sobre una población rural y un territorio que, históricamente, se ha desarrollado a partir de la producción primaria.

Mapa 1: Localización del partido de General Pueyrredón
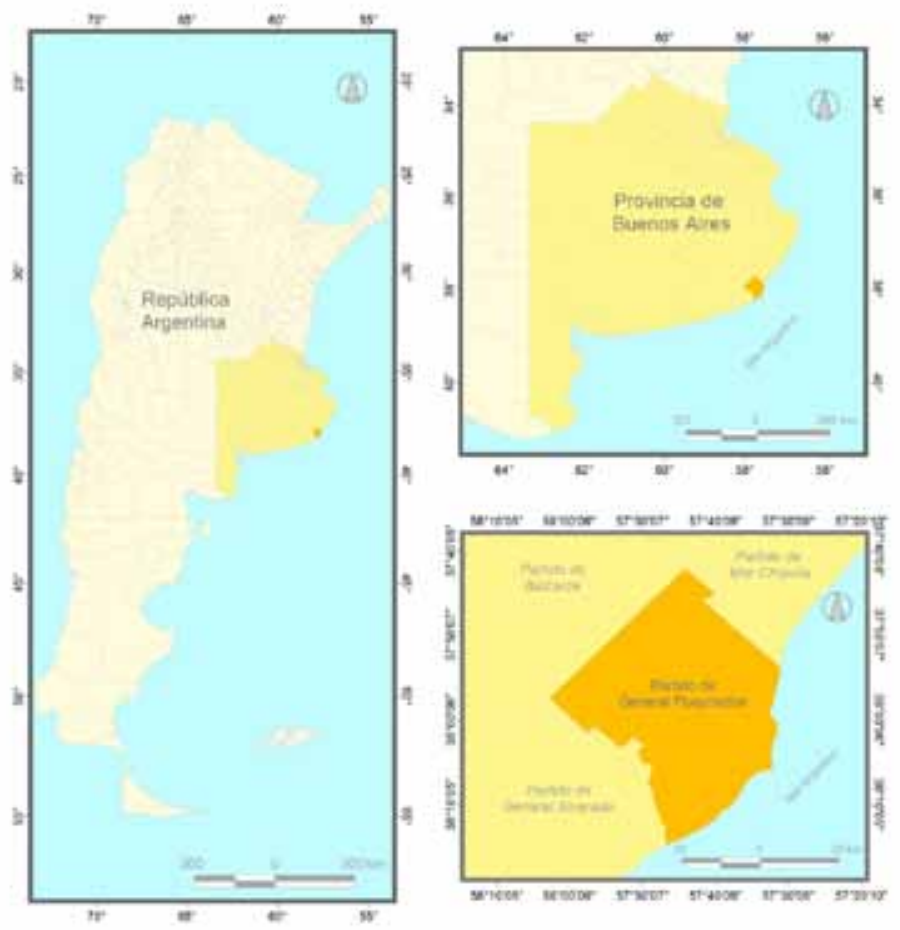

Fuente: Atlas Socio-territorial de Mar del Plata y el partido de General Pueyrredón (Lucero, 2010) 
Tabla 1: Establecimientos de turismo rural en Argentina según regiones

\begin{tabular}{|c|c|c|c|}
\hline Región & $\begin{array}{c}\text { Total de } \\
\text { establecimientos }\end{array}$ & $\begin{array}{c}\text { Establecimientos } \\
\text { con recreación y } \\
\text { turismo cultural }\end{array}$ & $\begin{array}{c}\text { Número } \\
\text { de plazas }\end{array}$ \\
\hline Pampeana & 457 & 269 & 2934 \\
\hline NEA & 122 & 99 & 429 \\
\hline NOA & 127 & 88 & 671 \\
\hline Cuyo & 123 & 92 & 412 \\
\hline Patagonia & 257 & 162 & 1346 \\
\hline
\end{tabular}

Fuente: elaboración personal sobre la base del Censo Nacional Agropecuario 2002 (INDEC)

General Pueyrredón es uno de los principales distritos pampeanos con oferta de explotaciones agropecuarias de ocio y turismo. Ocupa el décimo tercer lugar en cuanto a cantidad de establecimientos ofrecidos y el séptimo considerando tanto la cantidad de establecimientos con recreación y turismo cultural como el número de plazas (ver tabla 2$)^{3}$.

Tabla 2: Primeros quince partidos con establecimientos de turismo rural en la región Pampeana

\begin{tabular}{|l|c|c|c|}
\hline \multicolumn{1}{|c|}{ Partido y provincia } & $\begin{array}{c}\text { Total de } \\
\text { establecimientos }\end{array}$ & $\begin{array}{c}\text { Establecimientos } \\
\text { con recreación y } \\
\text { turismo cultural }\end{array}$ & $\begin{array}{c}\text { Número de } \\
\text { plazas }\end{array}$ \\
\hline Calamuchita (Córdoba) & 22 & 21 & 344 \\
\hline Loventué (La Pampa) & 20 & 4 & 80 \\
\hline Islas del Ibicuy (Entre Ríos) & 17 & 5 & 34 \\
\hline Punilla (Córdoba) & 16 & 12 & 58 \\
\hline Tornquist (Buenos Aires) & 12 & 13 & 148 \\
\hline Totoral (Córdoba) & 12 & 5 & 82 \\
\hline Utracán (La Pampa) & 10 & 2 & 43 \\
\hline Chascomús (Buenos Aires) & 9 & 3 & 33 \\
\hline San Alberto (Córdoba) & 9 & 4 & 76 \\
\hline Gualeguay (Entre Ríos) & 9 & 1 & 38 \\
\hline Gualeguaychú (Entre Ríos) & 9 & 3 & 104 \\
\hline Toay (La Pampa) & 9 & 2 & 42 \\
\hline Gral. Pueyrredón (Buenos Aires) & $\mathbf{8}$ & $\mathbf{4}$ & 69 \\
\hline Paraná (Entre Ríos) & 8 & 3 & 207 \\
\hline Uruguay (Entre Ríos) & 8 & 7 & 80 \\
\hline
\end{tabular}

Fuente: elaboración personal sobre la base del Censo Nacional Agropecuario 2002 (INDEC)

\footnotetext{
${ }^{3}$ Obsérvese que dentro de los quince distritos con mayor oferta de establecimientos de turismo rural se encuentran áreas donde el turismo es una importante actividad desde hace ya décadas. Al partido de General Pueyrredón lo acompañan otros como Calamuchita, San Alberto y Punilla, distritos serranos tradicionalmente turísticos pertenecientes a la provincia de Córdoba, también Gualeguay, Gualeguaychú e Islas del Ibicuy, áreas del sur de Entre Ríos que históricamente han recibido turistas por su cercanía a la Capital Federal.
} 
El historial turístico del partido data desde fines del siglo XIX, cuando Mar del Plata ${ }^{4}$ se consolidó como villa balnearia, para luego, hacia mitad de siglo XX, pasar a ser considerada ciudad emblemática del turismo masivo de sol y playa. En los últimos años la oferta de ocio y turismo excede la postal tradicional de la ciudad costera y empieza a incluir circuitos, paseos y establecimientos del espacio rural distrital. Al igual que la Secretaría de Turismo de la provincia de Buenos Aires, el Ente Municipal de Turismo de Mar del Plata también despliega estrategias de promoción que apuntan a revalorizar el espacio rural local y a ampliar la actividad turística, la cual históricamente se ha visto restringida al espacio urbano-costero y a los meses de verano. En uno de los folletos turísticos creados por esta institución se expresa:

Mar del Plata, ubicada a $404 \mathrm{Kms}$. de la capital argentina, no es ajena a los deseos de quienes buscan un auténtico descanso y le abre las "puertas al campo" invitándolo a conocer los establecimientos rurales del sudeste de la provincia de Buenos Aires. A no más de 30 minutos del centro de la ciudad, de sus playas y con el respaldo de un apropiado equipamiento turístico, podrá disfrutar de un día de campo en excursiones y paseos donde la naturaleza, la cultura, la historia y las tradiciones se conjugan para que goce de unas vacaciones con genuino sabor pampeano.

Dentro de este conjunto de establecimientos, excursiones y paseos que conforman la oferta de ocio y turismo rural local se encuentran dos estancias, La Reserva y La Trinidad (ver mapa 2), cuyas características se presentan a continuación:

a) Estancia La Reserva se compone de 355 hectáreas, el establecimiento brinda la posibilidad de pernoctar en el campo desde el año 2007. La estructura de alojamiento turístico se compone de dos residencias, una principal y otra secundaria, que permiten la estadía de hasta cuatro personas. Además de brindar un espacio de tranquilidad y contacto con la naturaleza, tiene como atractivos la muestra del proceso de producción artesanal de prendas confeccionadas con lana de oveja y llama y la realización de una visita guiada por las instalaciones de la antigua fábrica de quesos y dulces regionales La Cucharita, que funcionaba previo al turismo. De hecho, la actividad de servicio responde a la desindustrialización del establecimiento, permitiendo la ampliación de los ingresos y la ocupación del tiempo sobrante de su propietaria, quien cumple una doble función como productora tambera (actividad principal en la actualidad) y anfitriona turística (actividad complementaria).

b) Estancia La Trinidad ofrece uno de los restaurantes de campo más importantes de la región desde 1996. El servicio de comidas se ubica como actividad generadora de ingresos complementarios a los provenientes de la agricultura, aunque, como se apreciará más adelante, durante la década del

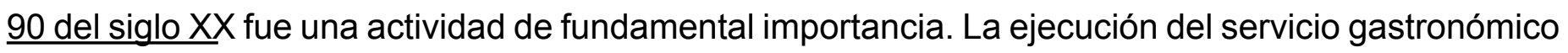
${ }^{4}$ Ciudad cabecera del partido. 
requirió de la refuncionalización de un depósito de insumos y maquinaria agrícola. Además, a este servicio se deben sumar tres hectáreas de verde, una exposición de instrumentos agrícolas de principios de siglo XX e infraestructura considerada de interés patrimonial por la Municipalidad de General Pueyrredón (matera, aljibe, antigua residencia de Jean Pierre Camet $^{5}$ ). La propietaria del lugar es la responsable de mantener la continuidad de la actividad de servicio. La folletería del lugar expresa:

Podrá sentir la hospitalidad y calidez del hombre de campo, junto a la personalísima atención de sus dueños.

El análisis que se presenta a continuación procede del relato de las propietarias de estas estancias y de la reflexión realizada sobre la base de la información empírica vinculada con la revalorización del espacio rural y la calidad de vida. Se trata de analizar cómo se califica al espacio rural y urbano, qué factores intervinieron en las estancias para poner en marcha la actividad, y cómo el ocio y turismo rural aportan una mejor calidad de vida a quienes lo demandan y lo ofrecen.

Mapa 2: Localización de las estancias testigos

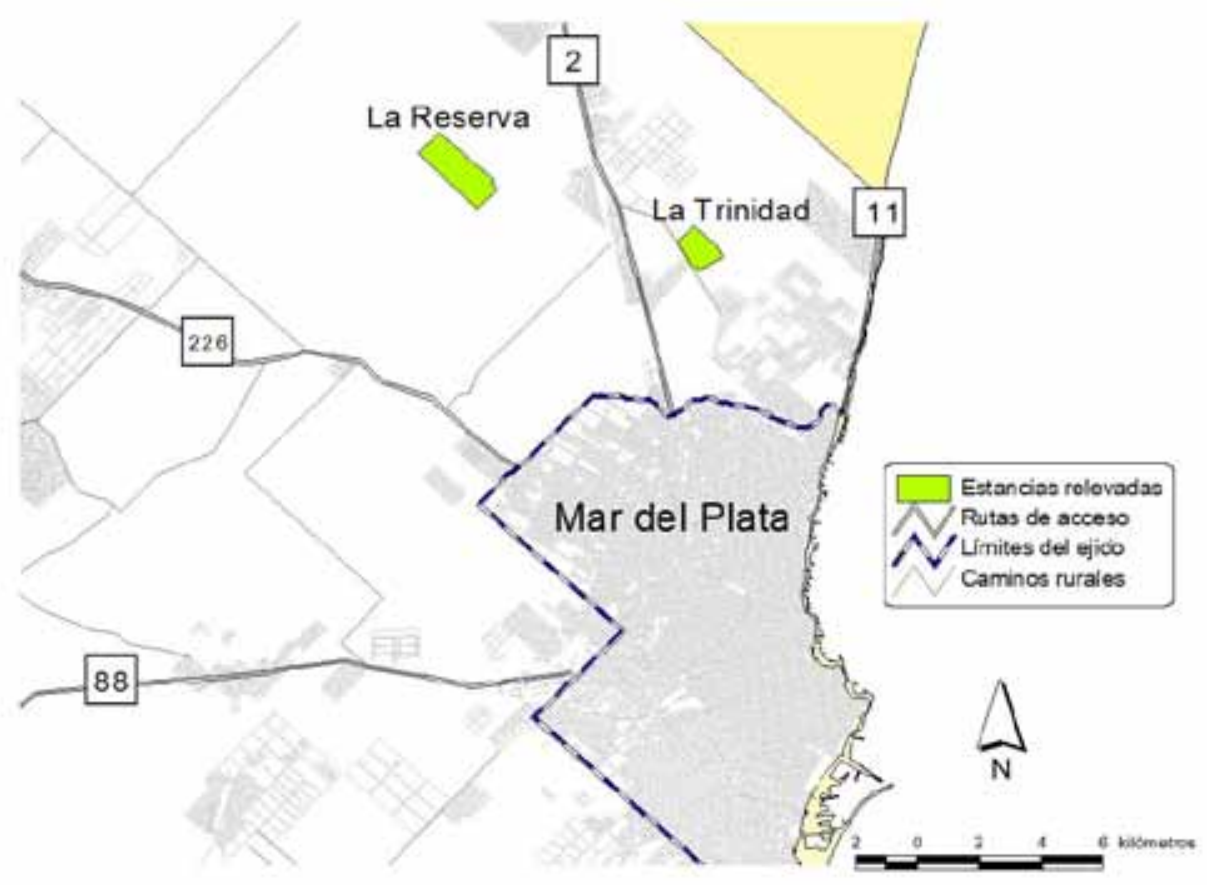

Fuente: Elaboración propia

\footnotetext{
${ }^{5}$ Francés que en 1862 fundó la estancia.
} 
a) Relato de la propietaria de la estancia La Reserva:

"Yo creo que la gente busca lugares alternativos para salir de la ciudad y que le hagan pasar un día diferente... se ha valorizado en el último tiempo mucho el tema de ir al campo, quizás antes no gustaba tanto, era más interesante realizar otro tipo de actividades, ahora como la vida está bastante agitada es como que se vuelve la necesidad de ir a lugares tranquilos, de naturaleza... y si vas en un grupo de personas en los cuales podes compartir es mucho más lindo todavía ¿no?

Un comentario lindísimo que me llegó este fin de semana que estuvo un matrimonio que vino a pasar una noche: realmente les encantó, la tranquilidad, la vegetación, les pareció un lugar maravilloso... el estar cerca de las llamas, ver como se ordeñan las vacas, todo ese contacto con lo típico del campo y al mismo tiempo poder comer un buen asado y disfrutar una tarde tranquila. Es lo que les hace feliz... y una cosa que es muy importante... la hospitalidad, es fundamental. Puede no ser perfecto el lugar, pero si vos estas atento a lo que necesitan...

[Respecto al lugar de origen de los turistas] Sorprendentemente, últimamente de toda la zona de Mar del Plata... o sea, varió un poquito [En un principio provenían principalmente de la Capital Federal y del exterior].

[Respecto de la actividad] Es un complemento... tenés que tener un ingreso fijo..."

Según la anfitriona turística y propietaria de la estancia, escapar de la ciudad es una necesidad cada vez más influyente en el accionar de la sociedad. En consecuencia, la búsqueda de contacto con el campo o un acercamiento a la naturaleza se vuelve una práctica creciente de los citadinos.

Nótese la apreciación del espacio rural como espacio sin atractivo antes y espacio revalorizado en la actualidad, utilizándose para describirlo adjetivos como lugar alternativo, tranquilo y natural. En contraposición, el espacio urbano es definido como ámbito del que hace falta salir, espacio donde se desarrolla una vida cada vez más agitada.

Se menciona que la finalidad de los turistas es pasar un día o un fin de semana diferente, es decir, tener la oportunidad de desarrollar prácticas atípicas, apreciar el entorno y vivir tiempos distintos de los cotidianos. Además, se agrega la posibilidad de compartir la experiencia con otros, hecho que implica un disfrute en simultáneo y el contacto directo entre las personas, aspectos que merman poco a poco conforme avanzan la urbanización y las tecnologías de la comunicación y la información. Podría decirse que, para los turistas, estas características constituyen un conjunto de dimensiones 
que conducen a una mejor calidad de vida.

En otro momento de la entrevista, se reconoce que en los últimos años la procedencia de los turistas ha cambiado a favor de la población local. El crecimiento demográfico de Mar del Plata podría ser una posible causa, ya que este proceso (ver tabla 3) forja el escenario ideal para el aumento de la demanda de espacios de ocio y turismo sobre el espacio rural circundante a la ciudad.

Tabla 3: La población marplatense según los últimos censos

\begin{tabular}{|c|c|c|c|}
\cline { 2 - 4 } \multicolumn{1}{c|}{} & 1991 & 2001 & 2010 \\
\hline Población total & 500.976 & 541.733 & 614.350 \\
\hline $\begin{array}{c}\text { Tasa de crecimiento } \\
\text { anual intercensal }\end{array}$ & - & 0,81 & 1,49 \\
\hline $\begin{array}{c}\text { Porcentaje de } \\
\text { marplatenses respecto } \\
\text { del distrito }\end{array}$ & 94 & 96 & 99 \\
\hline
\end{tabular}

Fuente: elaboración propia sobre la base de Censos de Población, Hogares y Viviendas (INDEC)

Además, por más que Mar del Plata esté incorporada al grupo de aglomeraciones de tamaño intermedio (ATI's), es decir, al conjunto de ciudades que en el rango nacional evidencian una escala humana óptima y buenos niveles de calidad de vida (Velázquez, G., 2008), ciertos procesos inherentes al crecimiento urbano como la inseguridad, la violencia, la contaminación ambiental y el ruido, sumados a la masificación turística durante los meses de temporada, vienen adquiriendo peso en la cotidianidad del habitante marplatense. Esto puede alterar las decisiones de la población local en lo que respecta a las áreas utilizadas con fines de ocio y redireccionar los flujos en favor del espacio rural.

Hacia el final del fragmento, se explicita que el turismo es una actividad complementaria, ya que poder desarrollar una oferta de este tipo requiere contar con un ingreso fijo. En este caso, la producción de leche aporta los principales ingresos del establecimiento.

Por fuera del momento de la entrevista, la propietaria de la estancia subraya que la prestación del servicio turístico derivó de dos grandes necesidades, por un lado, complementar los ingresos procedentes de la producción tambera, por otro, ocupar el tiempo sobrante generado por la 
desindustrialización del establecimiento. Al igual que muchas otras explotaciones agropecuarias del país, durante la década del 90 del siglo XX la estancia sufrió las consecuencias de la inaccesibilidad al crédito, la dificultad para incorporar tecnología y la competencia con otras empresas, perjudicándose poco a poco la elaboración de los dulces y quesos La Cucharita. Apréciese como un proceso macro, o el contexto social y económico de un momento determinado, se expresa en distintos lugares, siendo que, en esta estancia, el origen del ocio y turismo rural se relaciona con la búsqueda de una alternativa para asegurar el bienestar.

Antes de desarrollar la actividad de servicio, durante los primeros años del siglo XXI, la propietaria del lugar quiso realizar cursos y capacitaciones en Turismo Rural. Nótese como, además de obtener ingresos, la estrategia le ha significado un enriquecimiento personal desde el punto de vista de la instrucción, formación y acceso al conocimiento. A su vez, agrega que la tenencia de infraestructura ociosa y las ganas de embellecer el lugar, fueron factores tenidos en cuenta para desarrollar el turismo.

Con esta enumeración de características se trata de aclarar que una explicación sustancial del turismo en la estancia incluye una complejidad de factores, desde la necesidad de obtener ingresos hasta aspiraciones y deseos propios de la anfitriona. La satisfacción de cada una de estas necesidades, materiales y no materiales, representan el camino hacia los estándares de vida deseados.

Para concluir con esta unidad de observación, la estancia conserva algunos atractivos asociados con lo típico del campo, entre ellos, el relato seleccionado menciona el ordeñe de vacas, pero también incluye un recorrido guiado por la fábrica de quesos y dulces, sin producción en la actualidad, (ver foto 1), una muestra de objetos e instrumentos agropecuarios históricos (carretas, morteros, marcas de ganado) (ver foto 2) y la observación del proceso de elaboración de prendas artesanales en telar y a mano a partir de lana de llamas y ovejas (ver foto 3). Tanto objetos como acciones rurales se refuncionalizan y cambian su significado al incorporar al turismo en la estancia, permitiendo así la revalorización del campo. 


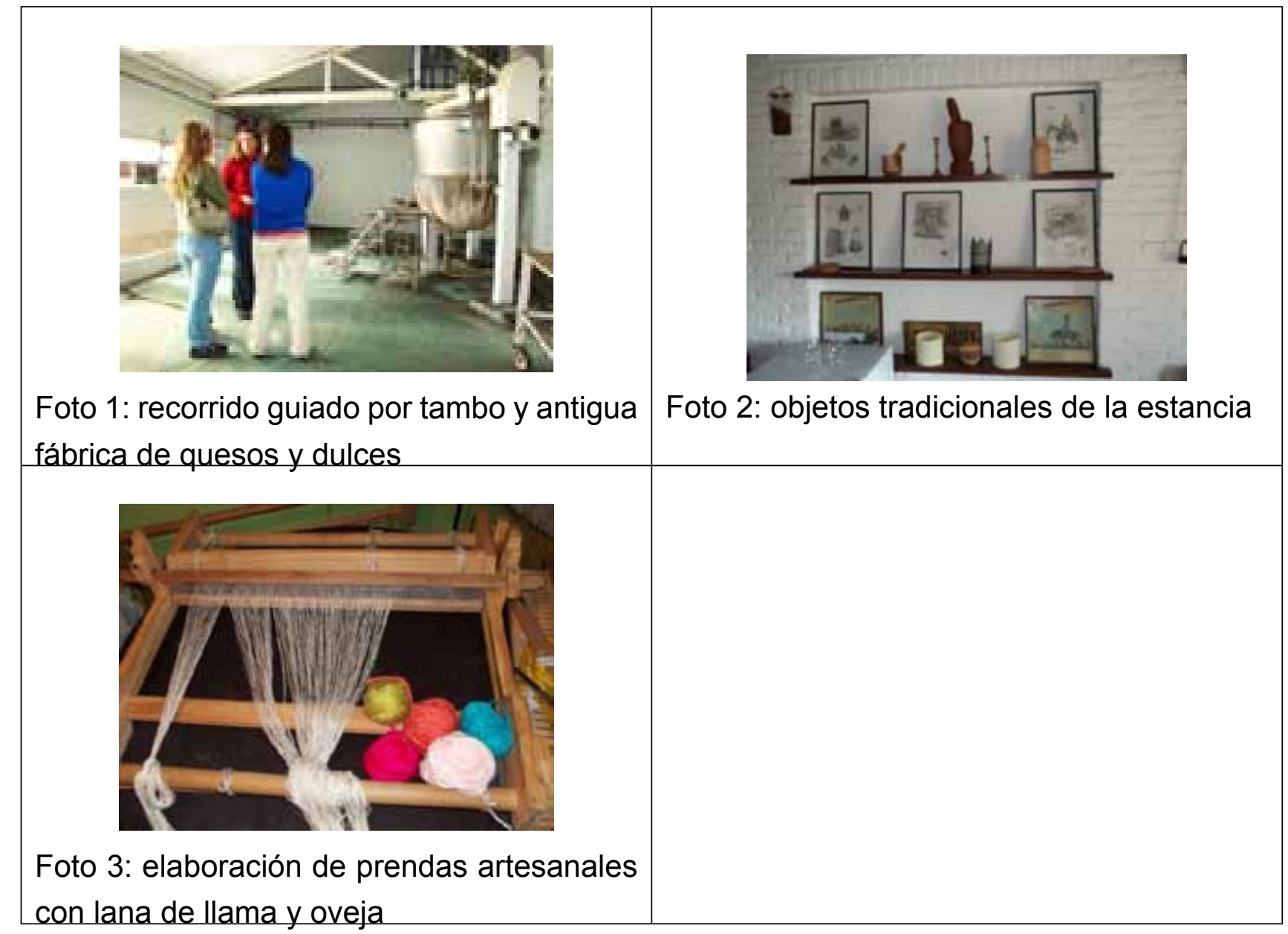

Fuente: archivo personal y www.estancialareserva.com.ar (ingreso en agosto de 2014)

b) Relato de la propietaria de la estancia La Trinidad:

"La gente que viene, viene a tener un momento de paz... tuve una cosa muy linda hace unos años... uno me dijo: quiero decirle que mi mujer- hacía no sé cuantos años que era totalmente autista, qué sé yo- recién acá me puede empezar a hablar... para mí fue una alegría tremenda, porque esa mujer había quedado muda... y aquí empezó a hablar... él la llevaba del brazo, unas personas grandes... increíble, eso me gratifica muchísimo.

Yo los veo acá: "no quiero saber nada de la ciudad, quiero esto, para mí es algo fantástico porque paso la tranquera y me olvido de la ciudad"... todos me dicen lo mismo.

Muchas veces me preguntan: por qué no hace alguna promoción, alguna cosa... y les digo que justamente yo lo que quiero es que no se llene esto de una cosa de esperar gente como loco... no, no quiero de ninguna manera, no me divierte como no le divierte a la gente que viene... Me Ilaman muchas veces por teléfono y me dicen: mire, me reserva tal mesa para dentro de tres meses por ejemplo... de Europa, de Estados Unidos... me Ilaman ellos directamente. 
[Respecto a los motivos que llevaron a impulsar la actividad de servicio] Ahora no tiene razón de ser, pero en esa época... 16 años calculale... década de los '90... fue tremendo porque mi hija se vino a vivir acá con mi yerno y con mis dos nietos... estaba toda la casa llena... les dije que no podía pagarles... la parte del campo no valía nada, todo era un desastre, entonces les dije: miren yo no tengo manera de pagarles a ustedes, la única manera es esta [se refiere a la utilización del establecimiento para la prestación de un servicio]. El personal me ayudó a mí a hacer todo... porque llegó un momento en que no tenía plata ni para pagarle a ellos... toda la gente ha dado una mano para poder salir a flote..."

Algunos de los aspectos detallados en el caso anterior surgen también en este segundo testimonio. El campo invita a vivir un momento de paz y tranquilidad; de forma contraria, la ciudad se presenta como espacio agobiante y a olvidar durante el momento de esparcimiento y el transcurso de las actividades recreativas. Los comentarios comunes de los turistas rescatados por la propietaria del establecimiento ponen de manifiesto que el contacto con el campo es una necesidad, e incluso esta experiencia puede llegar a repercutir sobre las relaciones entre las personas.

Para conservar las características demandadas por los visitantes, incluyendo a turistas internacionales, se menciona que no se despliegan estrategias de publicidad y promoción que puedan llegar a alterar los atractivos o las características de la oferta. La idea no es asemejar el servicio a los de tipo urbano, donde se vuelve frecuente esperar para sentarse a comer y ser atendidos. De esta manera, se evitan algunas de las externalidades negativas comunes en áreas de turismo rural, como la transformación de la experiencia turística en una mera mercancía y la contaminación (Roman y Cicolella, 2009). Nótese que la puesta en marcha de la actividad de servicio se debió, también, a la coyuntural situación por la que transcurrió la familia durante fines del siglo XX y a los bajos precios del sector agropecuario. La actividad del ocio y turismo se insertó como instrumento de diversificación de ingresos y mantenimiento de la mano de obra, frente a las vicisitudes del mercado agrario y los bajos valores de los productos desarrollados en el lugar.

En su origen, el ocio y turismo rural ocupaba un lugar más importante que en el presente, los ingresos provenientes de esta actividad representaban una entrada indispensable y un pilar del bienestar no sólo para la familia propietaria, sino también para los trabajadores agrícolas que residían en el lugar. Ambos grupos realizaron tareas para efectivizar el desarrollo de la actividad y así mantener sus condiciones de vida. Lograron que el casco de la estancia (ver foto 4) sea declarado de interés 
patrimonial por la Municipalidad de General Pueyrredón, colocaron carteles identificatorios con datos de ubicación e información histórica (ver foto 5) y arquitectónica, reconvirtieron un depósito de herramientas e insumos agrícolas en restaurante (ver foto 6) y emprendieron labores de servicio (recepción, camarería, cocina, limpieza), todo esto sin abandonar el trabajo correspondiente al sector agrícola.

No obstante, como se enuncia en el relato, "ahora no tiene razón de ser". Durante los últimos años el valor de los productos agrícolas ha ido aumentando y, por consiguiente, la importancia económica del ocio y turismo rural se ha reducido. La ejecución de una actividad compensadora ya no sería necesaria si se lo piensa en términos de ingresos. Sin embargo, la oferta de servicios se mantiene en funcionamiento.

En esta instancia del análisis es donde asoman características, destacadas en el marco teórico, aportadas por García y otros (2001), quienes explican la subsistencia del ocio y turismo en áreas rurales cuando es liderado por mujeres, y pese a haberse superado el período de crisis. Haber ganado un espacio propio, donde tomar decisiones, contar la historia del campo, sentir la gratificación de recibir visitantes y ser reconocida por ellos, llega a equiparar el factor económico ya que produce una satisfacción de necesidades no materiales asociadas con una mejor calidad de vida. Por medio de esta interpretación se comprende, en parte, la continuidad del servicio de comidas durante 16 años, aunque se haya superado la crisis económica familiar. Para la propietaria de la estancia, actualmente el restaurante representa parte de su identidad, así como brindar un servicio significa una forma de mantenerse vigente.

Aunque persista la actividad complementaria, las características de la oferta han variado en función de su menor dependencia económica. Pareciera que la diversidad de la oferta depende del grado de necesidad de ingresos complementarios, poniéndose en juego el tiempo a invertir y el gusto o las preferencias entre los distintos atractivos a ofrecer. Se presentan como ejemplos de esta dinámica la frecuencia del servicio y el tipo de oferta. Con respecto al primero, el restaurante sólo abre sus puertas los días domingo, cuando en un comienzo funcionaba más de un día a la semana. Con respecto al segundo, la posibilidad de realizar eventos (bodas, cumpleaños) fue descartada durante estos últimos años, ya que la propietaria subraya haber tenido malas experiencias. Estos cambios se deben a la menor necesidad de implementar el ocio y turismo rural en la estancia. 


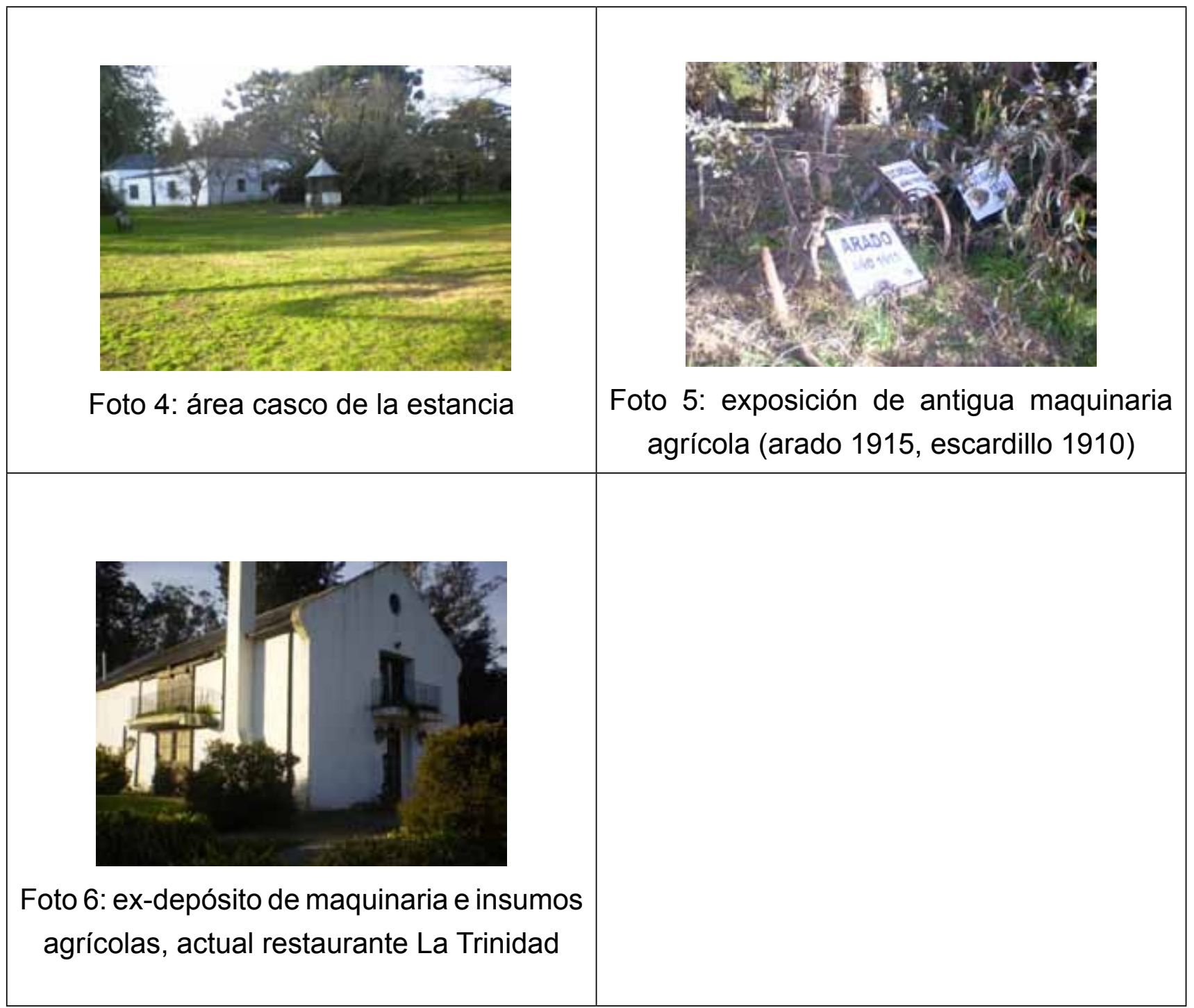

Fuente: archivo personal

Habiéndose conocido la forma en que se califica al espacio rural y urbano y los factores que intervinieron en cada estancia para poner en marcha el ocio y turismo rural como estrategia de diversificación de ingresos, a continuación se retoman en la tabla 4 los principales aspectos, surgidos e interpretados de las entrevistas, que aportan a comprender la forma en que el ocio y el turismo rural contribuyen a una mejor calidad de vida en quienes lo demandan y lo ofrecen: 
Tabla 4: Aspectos del ocio y del turismo rural que aportan a una mejor calidad de vida según las entrevistas

\begin{tabular}{|c|c|c|}
\hline & Turistas y visitantes & Anfitrionas \\
\hline $\begin{array}{c}\text { Estancia } \\
\text { La Reserva }\end{array}$ & $\begin{array}{l}\text {-pasar un día diferente; } \\
\text {-compartir una experiencia con } \\
\text { otras personas; } \\
\text {-entrar en contacto con la } \\
\text { naturaleza y lo típico del campo; } \\
\text {-recibir un trato de hospitalidad }\end{array}$ & $\begin{array}{c}\text {-complementar los ingresos } \\
\text { procedentes del agro; } \\
\text {-posibilidad de ocupar el tiempo } \\
\text { libre en una actividad de agrado; } \\
\text {-satisfacción de brindar un } \\
\text { espacio tranquilo y de naturaleza; } \\
\text {-mayor instrucción y acceso al } \\
\text { conocimiento }\end{array}$ \\
\hline $\begin{array}{l}\text { Estancia } \\
\text { La Trinidad }\end{array}$ & $\begin{array}{l}\text {-tener una instancia de paz; } \\
\text {-olvidar momentáneamente la } \\
\text { ciudad; } \\
\text {-posibilidad de una movilización } \\
\text { interna o emocional; } \\
\text {-recibir un trato personalizado sin } \\
\text { tener que esperar }\end{array}$ & $\begin{array}{l}\text {-complementar los ingresos } \\
\text { procedentes del agro; } \\
\text {-gratificación personal y diversión; } \\
\text {-afianzamiento de una identidad y } \\
\text { creación de un espacio propio; } \\
\text {-posibilidad de sostener a la } \\
\text { familia y asegurar un ingreso para } \\
\text { el personal de la estancia; }\end{array}$ \\
\hline
\end{tabular}

Fuente: elaboración propia

\section{¿Conclusión?}

Producto de su carácter exploratorio, el trabajo aquí desplegado no permite la presentación de conclusiones acabadas sino la posibilidad de formular una serie de interrogantes para el desarrollo de futuras investigaciones sobre la temática y el área de estudio.

Con respecto a la temática, haber indagado en el relato de quienes ofrecen ocio y turismo rural sirvió para aplicar la teoría sobre la revalorización del espacio rural y ver que, desde la voz de sus propios pobladores, el campo se reviste de nuevas adjetivaciones y significados que "realzan su autoestima”. Producto de este ejercicio, una de las principales incógnitas asumida es: ¿cuál es la opinión de los turistas y visitantes acerca de esta experiencia?, ¿se revalidan categorías al oír sus 
relatos, como por ejemplo el mayor contacto con la naturaleza o el recibir un trato personalizado? Se considera que sólo conociendo el comentario de ambas partes podrá avanzarse sobre la idea de que la búsqueda de una mejor calidad de vida es la causa principal del origen del ocio y turismo rural. Por otro lado, haber investigado sobre las adaptaciones requeridas para poner en marcha la actividad complementaria del ocio y turismo rural derivó en cuestionamientos como: ¿de qué forma se asumen en cada establecimiento los intentos de urbanizar y turistificar el campo?, ¿afecta la calidad de vida de los hombres y mujeres rurales la revalorización del espacio rural derivada de su turistificación? Con respecto al área de estudio, no es la primera vez que se analiza la revalorización del espacio rural y su relación con la calidad de vida en el partido de General Pueyrredón ${ }^{6}$. Sin embargo, carecían de aportes centrados en la arista de su turistificación. Quizás, la contribución más significativa del artículo haya sido haber incorporado el caso de un nuevo territorio al amplio debate sobre la trayectoria del ocio y turismo rural, la prestación de servicios en estancias, su origen y la convivencia entre estas actividades y las tradicionales.

A nivel territorial surgen preguntas como: ¿de qué forma se relacionan el área turística tradicional del partido de General Pueyrredón, es decir la costa marplatense, con los fragmentos de espacio rural turistificados?, ¿cómo se complementa un espacio con el otro? ¿Cómo difiere la construcción de atractividad referida al espacio rural entre partidos con una oferta turística heterogénea, como es el caso de General Pueyrredón, y partidos donde lo relacionado al campo se instala como principal o único atractivo turístico?, ¿los flujos de turistas y visitantes anhelantes de campo pampeano se ajustan a esta especialización del territorio?

Evidentemente, estudiar la relación entre el territorio, el espacio rural que lo conforma y la calidad de vida de sus habitantes permanentes y temporales es un hecho complejo. Haber iniciado un proceso de investigación a partir de una exploración basada en el enfoque micro de la calidad de vida, es decir, en la opinión de algunos de los sujetos implicados, fue de utilidad para reafirmar que, en primer lugar, factores materiales y no materiales nacidos tanto del espacio rural como del urbano sustentan el proceso de revalorización del espacio rural, y en segundo lugar, que una expresión territorial, como por ejemplo la turistificación de un espacio rural distrital, se explica a partir de procesos y hechos correspondientes a distintas escalas geográficas, comprendiendo desde el devenir socioeconómico del país hasta las dinámicas y problemáticas propias del lugar.

\footnotetext{
${ }^{6}$ Ver Mikkelsen, 2008.
} 


\section{Referencias bibliográficas}

Craviotti, C. (2002). Actividades turísticas y Nueva Ruralidad: análisis de experiencias en la cuenca del Abasto a Buenos Aires. Revista de Desarrollo Rural y Cooperativismo Agrario, № 6, pp. 89-106.

Cruz- Coria, E., Zizumbo Villareal, L., Cruz- Jiménez, G. y Quintilla- Montoya, A. (2012). Las dinámicas de dominación capitalista en el espacio rural: la configuración de paisajes turísticos. Cuadernos de Desarrollo Rural, 9 (69), pp. 151-174.

de Souza, E. (2012). Relación ciudad- campo y turismo rural. Ensayos teórico- metodológicos. Revista Estudios y Perspectivas en Turismo, Vol. 21, № 1, pp. 1-19.

Espil, M. (2005). Turismo de estancias. La construcción de representaciones acerca de una experiencia turística auténtica. Tesina de grado. Buenos Aires: UBA.

García, L., Dillón, B., Pombo, D., Calderón, C. Gebel, I. y Ambrosino, A. (2001). Turismo rural y género. Un estudio de caso. En Octavo Encuentro de Geógrafos de América Latina. Santiago de Chile, 4 al 10 de marzo de 2001. www.observatoriogeograficoamericalatina.org.mx/egal8/ Geografíasocioeconomica/Geografiaturistica/10.pdf (revisado en agosto de 2014).

Hiernaux, D. (2000). Las nuevas formas metropolitanas y su relación con el mundo rural. En P. Torres Lima (Comp.). Procesos metropolitanos y agricultura urbana (pp. 31-41). México: UAM- FAO.

López, M. (2007). La calidad de vida subjetiva y su relación con las experiencias recreativas en los espacios naturales. En VIII Jornadas Nacionales y II Simposio Internacional de Investigación- Acción en Turismo, Posadas, 7 a 9 de junio de 2007. www.eco.mdp.edu.ar/cendocu/repositorio/00470.pdf (revisado en agosto de 2014).

Lucero, P. (Dir.) (2010). Atlas Socio-territorial de Mar del Plata y el partido de General Pueyrredón. Mar del Plata: GESPyT- UNMdP.

Mikkelsen, C. (2008). La Calidad de Vida entendida en clave de la Revalorización Rural. En P. Lucero (Dir.). Territorio y Calidad de Vida, una mirada desde la Geografía Local. Mar del Plata y Partido de General Pueyrredon (pp. 283- 306). Mar del Plata: EUDEM.

Muñoz Escalona, F. (2013). Lo rural. Artículo periodístico. En Boletín- turístico, 14 de abril de 2013. www.boletin-turistico.com/component/k2/item/4707-lo-rural (revisado en agosto de 2014).

Nates Cruz, B. y Raymond, S. (2007). Buscando la naturaleza. Migración y dinámicas rurales contemporáneas. México: Anthropos. 
Nogar, A. y Capristo, M. (2010). Nuevos escenarios para los espacios rurales. El turismo rural como proceso emergente. En A. Nogar y G. Jacinto (Comp.). Los espacios rurales. Aproximaciones teóricas y procesos de intervención en turismo rural (pp. 103-127). Buenos Aires: La Colmena.

Pérez, E. (2001). Hacia una nueva visión de lo rural. En N. Giarraca (Org.). ¿Una nueva ruralidad en América Latina? (pp. 17-29). Buenos Aires: Clacso.

Posada, M. (1999). El espacio rural entre la producción y el consumo: algunas referencias para el caso argentino. En Revista Latinoamericana de Estudios Urbano Regionales, Vol. 25, № 75, pp. 6376.

Roman, F. y Ciccolella, M. (2009). Turismo rural en la Argentina. Concepto, situación y perspectivas. Buenos Aires: IICA.

Such Climent, M. y García Carretero, M. (2001). Turismo en espacios rurales. En D. Barrado y J. Calabuig (Eds.). Geografía Mundial del Turismo (pp. 185- 222). Madrid: Síntesis.

Tonon, G. y Castro Solano, A. (2011). Calidad de vida en Argentina: percepciones macro y micro sociales. Revista Estudios Políticos, N²7, pp. 157-171.

Troncoso, C. (2007). Atractivos y promoción del turismo: la construcción de atractividad turística de la provincia de Jujuy (Argentina). En Undécimo Encuentro de Geógrafos de América Latina. Bogotá, 26 al 30 de marzo de 2007. http://observatoriogeograficoamericalatina.org.mx/egal11/ Geografiasocioeconomica/Geografiaturistica/07.pdf (revisado en octubre de 2014).

Velazquez, G. (2008). Bienestar y jerarquía urbana. Análisis regional en la Argentina (2001). En P. Lucero (Dir.). Territorio y Calidad de Vida, una mirada desde la Geografía Local. Mar del Plata y Partido de General Pueyrredón (pp. 41-72). Mar del Plata: EUDEM.

\section{Fuentes de datos}

Folletería de la Secretaría de Turismo de la Provincia de Buenos Aires 2011 y 2012

Folletería del Ente Municipal de Turismo de Mar del Plata 2011 y 2012

Censos Nacionales de Población, Hogares y Viviendas 1991, 2001 y 2010. INDEC

Censo Nacional Agropecuario 2002. INDEC 